\title{
Children are not young adults: a call for standardized guidelines for dealing with pediatric patients in the emergency department of Canadian community hospitals
}

\author{
Muhammad A. Hamid, MBBS, DCH*; Sohaib Siddiqui, MB, BCh, BAO*; Ayesha Chandna, MBBS;
} Aliya Ariz, MBBS; Dennis Scolnik, MB, ChB†

Emergency departments deal with a spectrum of sick, distressed, and critically ill patients. For many patients, especially children, experiencing an emergency department can be a traumatic experience in itself. One personal experience firmly etched in the principal author's mind is of a mother in the emergency department desperately trying to cover her 5-year-old daughter's eyes and ears to shield her from the screams of a nearby adult in pain, and the swearing of another disgruntled patient. Unfortunately, scenarios like these will inevitably arise in Canadian community hospital emergency departments, where children routinely share waiting and treatment areas with adult patients. We propose that a standardized Canadian guideline be developed to improve the environment and facilities provided to children in such combined emergency departments (cEDs). Such a guideline will hopefully improve the quality of health care for both pediatric and adult patients, while standardizing facilities available to children outside of specialized tertiary pediatric centres.

Currently, Canadian emergency departments are not required to meet standards that address the specific needs of their pediatric patients, leading to potentially harmful variations in the environment and services provided to children. International literature and guidelines have emphasized that implementing a childfriendly environment, appropriate prehospital assessment, and pediatric-appropriate hospital staff and training are the most important tenets for catering to children in cEDs. The International Federation of Emergency Medicine has also stressed that establishing standards or guidelines of care for pediatric patients "assists both managers and clinical staff to deliver improvements." Children represent a significant proportion of patients attending emergency departments; $30 \%$ in Canada, $22.1 \%$ in the United States, and 26.5\% in the United Kingdom. ${ }^{2-4}$ In the United States, only $7 \%$ of these patients will be treated in a space designed to accommodate pediatric patients. ${ }^{5}$ In Ontario, the number is slightly higher with $14.9 \%$ of children being treated in specialized pediatric facilities. ${ }^{6}$ The remaining children will access cEDs within community hospitals. Ideally, a minimal standardized level of care should be provided to all children in Canada, irrespective of which hospital such children attend.

Currently, there are three national guidelines (United States, United Kingdom, and Australia), which address the care of children in $\mathrm{cED}$; however, no comparable guidelines are available for Canadian cEDs. In the United States, The Joint Policy Statement: Guidelines for the Care of Children in Emergency Departments (2009) and The National Paediatric Readiness Project were implemented to improve pediatric care in cEDs. ${ }^{7,8}$ In the United Kingdom, the Standards for Children and Young People in Emergency Care Settings 2012 outlines a standardized approach and also provides a framework to measure improvement. ${ }^{9}$ In Australia, The Guidelines on Emergency Department design (2007) outline the importance of specific pediatric treatment areas and equipment. ${ }^{10} \mathrm{We}$ envision similar protocols for Canadian cEDs, incorporating aspects of the aforementioned international guidelines. However, we feel that such guidelines should be developed with a

From the ${ }^{*}$ Rouge Valley Health System, Toronto, ON; and ${ }^{\dagger}$ Hospital for Sick Children, Toronto, ON.

Correspondence to: Dr. Muhammad A. Hamid, Rouge Valley Health System, 2867 Ellesmere Road, Toronto, ON M1E 4B9; Email: mahamid@rougevalley.ca 
Canadian context in mind. Canada is a vast country with both urban and rural environments, incorporating a wide diversity of patient demographics. Our guidelines should accommodate the needs of our unique patients and should work in unison with our health care system. Although there are obvious practical and financial limitations to providing extensive pediatric facilities in every Canadian hospital, establishing standardized guidelines would allow us to prioritize the most vital features applicable to all community hospitals.

Based on a review of current existing guidelines, there are at least four areas that could be addressed in a Canadian guideline aimed at standardizing children's care: triage, emergency department environment, equipment, and training.

\section{TRIAGE}

Prehospital and emergency department triage are essential to optimal management of pediatric patients. Understandably, separate facilities and entrances for pediatric patients may not be logistically or financially feasible for every hospital. However, some hospitals may be able to arrange a separate pediatric entrance to the emergency department, where health care workers specifically trained to assess and treat pediatric patients can be placed. Children should be efficiently triaged using the pediatric Canadian Triage and Acuity Scale. ${ }^{11}$ Standardized weight scales should be used to record the weight of every patient to facilitate weight-appropriate doses of medication and decrease the likelihood of dosing errors. ${ }^{12}$

\section{Pain assessment}

This can be a challenging aspect of triage in pediatric populations, because they may be at a pre-verbal state or have difficulty in verbalizing their symptoms. Standardized pediatric pain scales such as the Wong-Baker FACES pain scale, McGill pain questionnaire, or the visual analogue scale for measuring acute pain should be made available for triage staff. ${ }^{13-15}$

\section{EMERGENCY DEPARTMENT ENVIRONMENT}

The environment of an emergency department can have a direct influence on a child's care and level of anxiety during his or her visit. Children experience a significant level of anxiety and distress when they visit a hospital, because they are concerned about unfamiliar health care professionals, procedures, and uncertainties regarding their outcome. ${ }^{16}$ It has been shown that it is more difficult to obtain a history and conduct an examination on an anxious child. ${ }^{17}$ Environmental constraints can have potentially adverse outcomes, as highlighted in a Korean study, which showed a correlation between overcrowding in $\mathrm{cED}$ and increased mortality. ${ }^{18}$

\section{Separation from adults}

The facilities in cEDs should ideally allow for separate waiting, treatment, and resuscitation areas for children. ${ }^{19}$ In certain cases, having a specific pediatric resuscitation area is not feasible. In such cases, shared spaces should have ease of access to pediatric-appropriate equipment and resuscitation algorithms. ${ }^{5}$ Hospital environments that have specialized staff, equipment, and facilities that are geared toward children are most appropriate for treating pediatric patients under the age of $16 .^{20}$ Guidelines in the UK, for example, suggest that for every 5000 pediatric patients attending a $\mathrm{cED}$, there should be a separate, secured child-friendly cubicle designed to meet their needs and to accommodate their caregivers. ${ }^{9}$ Access to these areas should be controlled and secured from potentially aggressive adult patients. ${ }^{1}$ Specialized pediatric observational areas or short stay units can help monitor unstable patients and better address their needs and avoid any unnecessary transfers. ${ }^{1}$ However, if such transfers to tertiary or specialized centres are necessary, because many rural facilities lack extensive pediatric care, standardized patient criteria should be established to determine when such a transfer would be appropriate.

\section{Physical environment}

It is important to recognize that pediatric patients encompass a spectrum of developmental stages from infancy to adolescence and that each has unique requirements. Infants are highly dependent on their caregivers to meet their basic needs; therefore, provisions should be made for diaper changing and breastfeeding facilities. ${ }^{2}$ Such initiatives have already begun to be implemented in Ontario hospitals via the Baby Friendly Initiative. ${ }^{21}$ Toddlers will curiously explore their environment and therefore spaces should be void of potential hazards. Children's spaces should 
be equipped with age-appropriate "toys and books that comply with health and safety regulations" and those that adhere to infectious disease guidelines. ${ }^{9}$ For example, infectious disease guidelines recommend using germ-resistant fabrics that allow for easy disinfection. Therefore, any equipment or toys in child-friendly areas must be conducive to disinfection. Provisions for adolescent children should also be considered, and waiting areas should be equipped with health promotional material regarding issues such as sexual health, drugs, and smoking. ${ }^{6}$ Internationally, the Patient-and-Family-Centered Care (PFCC) model is becoming more popular and has been shown to improve clinical outcomes. ${ }^{5,21,22}$ This model promotes family presence and involvement during critical periods of care to help alleviate anxiety relief and promotes patient autonomy.

\section{EOUIPMENT}

Pediatric training must also focus on familiarity and experience with pediatric-appropriate equipment, which is vital in emergency situations. Unique anatomical considerations in the pediatric population mandate accessibility to pediatric-appropriate equipment and training within cEDs. ${ }^{5}$ A Canadian study was conducted in order to determine the availability of pediatric equipment in cEDs across Canada and found alarming deficiencies in the availability of pediatric-appropriate equipment. ${ }^{2}$ Because $5 \%$ of children presenting to cEDs are critically ill, ${ }^{3}$ such deficiencies in equipment can seriously hamper treatment. As part of future research, we intend to assess the current level of availability of pediatric-appropriate equipment and help mitigate any potential deficiencies.

\section{TRAINING}

Pediatric-appropriate training is a vital aspect in treating children in the emergency department. Health care professionals who deal with pediatric patients should have appropriate training in managing and communication to children and parents. ${ }^{20}$ Having access to aptly skilled staff, resuscitation algorithms, and appropriate pediatric dosing in resuscitation situations has been shown to improve patient outcomes and reduce mortality. ${ }^{5}$ Hospitals should facilitate and promote adherence to refresher training courses such as paediatric advanced life support (PALS), advanced cardiac life support (ACLS), and neonatal resuscitation program (NRP) for emergency staff in order to keep up to date with current practices.

Access to pediatric-trained clinicians and health care workers are vital for managing children because they have unique presentations and conditions. U.S. surveys suggest that only $23 \%$ of the children attending the emergency department will be seen by pediatric emergency medicine physicians. ${ }^{5}$ For example, guidelines in the UK recommend that emergency departments that treat more than 16,000 pediatric patients annually should be permanently staffed by a pediatric emergency medicine physician. ${ }^{9}$ Similarly, studies should be carried out in a Canadian context to establish a reasonable volume of pediatric patients treated at a facility, which would justify the presence of permanent pediatric staff in a community hospital. Integration of specialized staff, such as child-life specialists, can help reduce stress and promote the well-being of children under emergency circumstances. $^{23}$ They can also be employed during unpleasant medical interventions to provide distraction. ${ }^{1}$ Children and their caregivers should have access to pediatric social workers in cEDs to holistically address their needs. ${ }^{5}$

Canada has an exceptionally high standard of health care, and the care provided in most cED is exemplary. Nevertheless, emulating comparably developed countries by implementing standardized guidelines for the management of children in these settings would further improve the standard of care for pediatric emergency patients across the country. Children are the precious future of Canada. They deserve to be looked after in a cED that adheres to a minimum standard of practice enshrined in a Canadian-centric guideline ensuring child-appropriate triage, emergency department environment, equipment, and training.

Keywords: Canada, child, children, emergency department, guidelines, pediatric

Competing interests: None declared.

\section{REFERENCES}

1. International Federation for Emergency Medicine. 2012, International standards of care for children in emergency departments; 2012. Available at: http://www.ifem.cc/site/ DefaultSite/filesystem/documents/Policies\%20and\%20Guide lines/Paeds\%20standards\%20full\%20document-\%20final $\% 20040912$.pdf (accessed 14 October 2014). 
2. McGillivray D, Nijssen-Jordan C, Kramer MS, et al. Critical paediatric equipment availability in Canadian hospital emergency departments. Ann Emerg Med 2001;37(4):371-6.

3. Schappert S, Bhuiya F. Availability of pediatric services and equipment in emergency departments: United States, 2006. National Health Statistics Reports 2012;47:1-22. Available at: http://www.cdc.gov/nchs/data/nhsr/nhsr047.pdf (accessed 1 October 2014).

4. Health and Social Care Information Center. Accident and emergency attendances in England - 2012-13; 2014. Available at: http://www.hscic.gov.uk/catalogue/PUB13464 (accessed 2 October 2014).

5. Stone KP, Woodward GA. Paediatric patients in the adult trauma bay- comfort level and challenges. Clin Pediatr Emerg Med 2010;11(1):48-56.

6. Canadian Institute for Health Information. Emergency departments and children in Ontario; 2008. Available at: https://secure.cihi.ca/estore/productFamily.htm?pf=PFC100 8\&lang=en\&media $=0$ (accessed 4 October 2014).

7. American Academy of Paediatrics, Committee on Paediatric Emergency Medicine, American College of Emergency Physicians, Paediatric Committee, Emergency Nurses Association Paediatric Committee. Joint policy statementguidelines for care of children in the emergency department. Paediatrics 2009;124(4):1233-43.

8. National Pediatric Readiness Project. Available at: http:// www.pediatricreadiness.org/ (accessed 4 October 2014).

9. Royal College of Paediatrics and Child Health. New standards for emergency care of children and young people; 2012. Available at: http://www.rcpch.ac.uk/news/newstandards-set-emergency-care-children-and-young-people (accessed 1 October 2014).

10. Australian College for Emergency Medicine. Emergency Department Design Guidelines; 2007. Available at: https:// www.acem.org.au/getattachment/cde7e04a-fb7d-423a-bfef$217965809 \mathrm{~d} 7 \mathrm{a} /$ Emergency-Department-Design.aspx (accessed 1 October 2014).

11. Warren DW, Jarvis A, LeBlanc L, Gravel J, CTAS National Working Group (NWG). Revisions to the Canadian Triage and Acuity Scale Paediatric Guidelines (PaedCTAS). C7EM 2008;10(3):224-32.

12. Stucky ER. American Academy of Paediatrics, Committee on Drugs and Committee on Hospital Care. Policy statement: prevention of medication errors in the paediatric inpatient setting. Paediatrics 2003;112(2):431-6.

13. Garra G, Singer AJ, Taira BR, et al. Validation of the Wong-Baker FACES Pain Rating Scale in paediatric emergency department patients. Acad Emerg Med 2010; 17(1):50-4.

14. Melzack R. The McGill Pain Questionnaire: major properties and scoring methods. Pain 1975;1(3):277-99.

15. Bijur PE, Silver W, Gallager EJ. Reliability of the visual analog scale for measurement of acute pain. Acad Emerg Med 2001;8(12):1153-7.

16. Coyne I. Children's experiences of hospitalization. 7 Child Health Care 2006;10(4):326-36.

17. Athey J, Dean JM, Ball J, et al. Ability of hospitals to care for paediatric emergency patients. Pediatr Emerg Care 2001;17 (3):170-4.

18. Cha W, Shin SD, Cho JS, et al. The association between crowding and mortality in admitted paediatric patients from mixed adult-paediatric emergency departments in Korea. Ped Emerg Care 2011;27(12):1136-41.

19. Royal College of Paediatrics and Child Health. Emergency and urgent care - policy updates, commissioning and clinical guidelines. Available at: http://www.rcpch.ac.uk/emergen cycare (accessed 10 October 2014).

20. Scottish Government Emergency Care Framework for Children and Young People in Scotland; 2006. Available at: http://www.scotland.gov.uk/Publications/2006/09/19153348/6 (accessed 14 October 2014).

21. Baby Friendly Initiative Ontario. Available at: http://www. bfiontario.ca/ (accessed 16 October 2014).

22. O'Malley PJ, Brown K, Krug SE. Patient and familycentered care of children in emergency department. Paediatrics 2008;122(2):e511-21.

23. Wilson JM. Child life services. Paediatrics 2006;118(4):1757-63. 